\title{
Emergency physicians' attitudes and perceived barriers to the implementation of take-home naloxone programs in Canadian emergency departments
}

\author{
Lauren Lacroix, MD*; Lisa Thurgur, MD, MSc*; Aaron M. Orkin, MD, MSc, MPH ${ }^{\ddagger \S}$; \\ Jeffrey J. Perry, MD, MSc ${ }^{*}$; Ian G. Stiell, MD, $\mathrm{MSc}^{*}$
}

\section{ABSTRACT}

Objectives: Rates of opioid-related deaths have reached the level of national public health crisis in Canada. Communitybased opioid overdose education and naloxone distribution (OEND) programs distribute naloxone to people at risk, and the emergency department (ED) may be an underutilized setting to deliver naloxone to these people. The goal of this study was to identify Canadian emergency physicians' attitudes and perceived barriers to the implementation of take-home naloxone programs.

Methods: This was an anonymous Web-based survey of members of the Canadian Association of Emergency Physicians. Survey questions were developed by the research team and piloted for face validity and clarity. Two reminder emails were sent to non-responders at 2-week intervals. Respondent demographics were collected, and Likert scales were used to assess attitudes and barriers to the prescription of naloxone from the ED.

Results: A total of 459 physicians responded. The majority of respondents were male $(64 \%)$, worked in urban tertiary centres (58.3\%), and lived in Ontario (50.6\%). Overall, attitudes to OEND were strongly positive; $86 \%$ identified a willingness to prescribe naloxone from the ED. Perceived barriers included support for patient education (57\%), access to follow-up (44\%), and inadequate time (37\%). In addition to people at risk of overdose, $77 \%$ of respondents identified that friends and family members may also benefit.

Conclusions: Canadian emergency physicians are willing to distribute take-home naloxone, but thoughtful systems are required to facilitate opioid OEND implementation. These data will inform the development of these programs, with emphasis on multidisciplinary training and education.

\section{RÉSUMÉ}

Introduction: La mortalité liée à la prise d'opioïdes au Canada a pris une telle ampleur qu'elle est devenue une crise nationale en matière de santé publique. Les programmes communautaires d'enseignement sur les surdoses d'opioïdes et de distribution de naloxone rendent possible la remise de ce médicament aux personnes à risque, et le service des urgences (SU) serait un lieu sous-utilisé de distribution de naloxone aux personnes concernées. L'étude avait donc pour but de cerner les attitudes des médecins d'urgence au Canada à l'égard des programmes de distribution de naloxone ainsi que la perception des obstacles possibles à leur mise en œuvre.

Méthode: II s'agit d'une enquête anonyme, menée sur le Web parmi les membres de l'Association canadienne des médecins d'urgence. L'équipe de recherche a travaillé à l'élaboration des questions, puis a vérifié la validité apparente et la clarté du questionnaire. Deux rappels ont été envoyés par courriel aux non-répondants, à deux semaines d'intervalle. II y a eu collecte de données démographiques sur les répondants, et les attitudes des urgentologues à l'égard de la prescription de naloxone à partir des SU ainsi que les obstacles à cette nouvelle pratique ont été évalués à l'aide d'échelles de Likert.

Résultats: Au total, 459 médecins ont répondu à l'enquête. La majorité d'entre eux étaient des hommes (64\%), travaillaient dans des centres de soins tertiaires en milieu urbain $(58,3 \%)$ et demeuraient en Ontario $(50,6 \%)$. Les répondants se sont montrés, en général, grandement favorables à l'égard de ces programmes : en effet, $86 \%$ étaient disposés à prescrire de la naloxone à partir du SU. Toutefois, les obstacles perçus à la mise en œuvre de ces programmes comprenaient le manque de soutien pour l'enseignement aux patients ( $57 \%)$, la difficulté du suivi (44\%) et le manque de temps (37\%). Par ailleurs, $77 \%$ des répondants ont indiqué que, outre les personnes susceptibles de subir une surdose, les parents et les amis pouvaient profiter de ces programmes.

Conclusions: Les médecins d'urgence au Canada se montrent disposés à distribuer de la naloxone pour usage ultérieur, mais,

From the *Department of Emergency Medicine and tOttawa Hospital Research Institute, University of Ottawa, Ottawa, ON and $¥$ Schwartz/ Reisman Emergency Medicine Institute, Mount Sinai, Toronto, ON; and the §Dalla Lana School of Public Health and Department of Family and Community Medicine, University of Toronto, Toronto, ON.

Correspondence to: Dr. Lauren Lacroix, Department of Emergency Medicine, The Ottawa Hospital, 1053 Carling Avenue, E-Main Room EM-206, Box 227, Ottawa, ON K1Y 4E9: Email: Ilacroix@qmed.ca 
pour ce faire, il faut mettre en place des systèmes bien conçus afin de faciliter l'enseignement sur les surdoses d'opioïdes et la distribution de naloxone. Les données recueillies aideront à l'élaboration de ces programmes, accompagnés d'un volet important de formation et d'enseignement multidisciplinaires.

Keywords: emergency department, naloxone, opioids

\section{INTRODUCTION}

Unintentional overdose has become the leading cause of injury-related death among Americans ages 25 to 64 years. $^{1}$ A comparable epidemic is under way in Canada, ${ }^{2}$ with opioid misuse now the third-leading cause of accidental death in Ontario. ${ }^{3,4}$ The World Health Organization has recommended the use of naloxone by lay responders for treatment of overdose, ${ }^{5}$ and it has recently been added to the 2015 American Heart Association (AHA) guidelines for cardiac arrest. ${ }^{6}$ Health Canada recently removed the drug from the Prescription Drug List to increase access, making it available in Canadian pharmacies without a prescription. ${ }^{7}$

Community-based opioid overdose prevention and naloxone distribution programs have been operational in the United States and Europe since the mid-1990s but are still relatively novel in Canada. These programs involve training people at risk of opioid overdose and their friends and family members with the skills to identify overdose situations, activate emergency medical services, and provide basic life support interventions, including the administration of intramuscular or intranasal naloxone. ${ }^{8,9}$ Program participants are provided with a naloxone kit containing the program's training protocol, naloxone, and delivery devices. These programs have had success through overdose education and distribution of naloxone kits in several major Canadian cities, ${ }^{10-12}$ with several community reversals of opioid overdoses reported and no adverse effects. The World Health Organization, U.S. Centers for Disease Control and Prevention, and the U.S. Society of Toxicology have all advanced statements supporting these interventions and calling for wider access to these programs. ${ }^{13-15}$

Due to the high rate of drug-related visits, ${ }^{16}$ recurrent opioid prescribing, and routine encounters with opioid overdose patients, ${ }^{17}$ the emergency department (ED) may represent an underutilized setting to identify patients at risk of opioid overdose and to distribute naloxone.

To expand outpatient overdose education and naloxone distribution (OEND) programs from the ED, physicians' attitudes toward the programs and willingness to participate need to be evaluated. The objective of our study was to identify Canadian emergency physicians' attitudes and perceived barriers to the implementation of take-home naloxone programs.

\section{METHODS}

\section{Study design and population}

We conducted a self-administered, anonymous, and confidential Web-based survey of emergency medicine (EM) resident and attending physician members of the Canadian Association of Emergency Physicians (CAEP). A total of 1,658 physicians consented to receive surveys from the organization and were emailed a link to the survey using the Survey Monkey platform. ${ }^{18}$ Participation was voluntary. CAEP physicians not practicing EM or who were not members of CAEP were excluded.

\section{Survey content and administration}

Fourteen survey questions (see Supplementary Material) were developed by the research team and piloted amongst a group of emergency physicians for face validity and clarity prior to distribution. ${ }^{19} \mathrm{We}$ constructed the initial survey questions based on expert opinion and review of the evidence. ${ }^{20-22} \mathrm{We}$ then conducted cognitive interviews with practicing emergency physicians, where the physicians responded to the survey. During this assessment, they were asked to vocalize anything that they felt was either unclear, uncomfortable, or any other thoughts they might have. Body language was observed as well, and physicians were questioned about what they were thinking if they appeared to be perplexed or uncomfortable. The final survey tool also included basic demographic information such as gender, EM certifications, years of experience, and practice setting. After the initial email distribution, two further electronic reminders were sent according to a modified Dillman method. ${ }^{23}$ All survey responses were collected electronically and 
anonymously. As an incentive, participants were invited to enter their email on a separate website upon survey completion for a chance to win a $\$ 250$ gift certificate. The Ottawa Health Science Network Research Ethics Board approved this study.

\section{Data analysis}

Frequencies and means were calculated for each survey question, and a cross-tabulation chi-square analysis was performed for association of knowledge and barriers with the demographic information collected. All responses were used in the analysis.

\section{RESULTS}

A total of 459 physicians responded to the survey (response rate was $27.7 \%$ ). Respondents are mostly male $(63.9 \%)$, work in an urban tertiary centre $(58.3 \%)$, and have a Certification in the College of Family Physicians (CCFP) EM designation (44.9\%; Table 1). The majority of respondents reported prior knowledge of OEND programs $(77.6 \%)$, mostly through popular media sources $(59.4 \%)$, from a colleague/at a conference $(54.2 \%)$, or scholarly media or journal (33\%). A small proportion of respondents $(14.5 \%)$ had cared for a patient involved

\begin{tabular}{lr|}
\hline Table 1. Characteristics of survey respondents & \\
\hline Characteristic & $\mathrm{N}=459$ \\
\hline Male (\%) & 281 (63.9) \\
Training (\%) & \\
$\quad$ CCFP-EM & $197(44.9)$ \\
FRCPC & $124(28.2)$ \\
CCFP & $45(10.3)$ \\
Pediatric EM & $4(0.9)$ \\
Resident & $69(15.7)$ \\
Hours of patient care/week (mean, SD) & $28.5(11.1)$ \\
Hospital type (\%) & \\
$\quad$ Urban tertiary centre & $256(58.3)$ \\
Community hospital & $151(34.4)$ \\
Rural/remote hospital & $32(7.3)$ \\
Region of employment (\%) & \\
Ontario & 221 (50.6) \\
Prairies & $82(18.8)$ \\
Western & 80 (18.3) \\
Maritimes & $29(6.6)$ \\
Quebec & $25(5.7)$ \\
& \\
\hline CCFP = Certification in the College of Family Physicians (Canada); CCFP- \\
EM = Certification in the College of Family Physicians (Canada) with special competence \\
in Emergency Medicine; FRCPC = Fellow of the Royal College of Physicians of Canada. \\
\hline
\end{tabular}

in OEND programs, whereas $13.9 \%$ reported a direct involvement with OEND programs.

Respondents showed a positive attitude toward opioid OEND programs, with $86 \%$ reporting that they would be willing to prescribe or distribute naloxone from the ED (Figure 1). The chi-square analysis did not reveal a significant difference in willingness to prescribe based on gender $(p=0.09)$, practice setting $(p=0.74)$, or number of years in practice $(p=0.13)$. The data analysis did reveal a significant association between willingness to prescribe naloxone and EM credentials or province/territory of practice; physicians with a CCFP-EM designation were less likely to distribute naloxone $(p<0.01)$, as were physicians from the Maritimes $(p<0.01)$.

Survey respondents' identified barriers to participation in opioid OEND programs are represented in Figure 2. Perceived barriers included lack of allied health support for patient education (57\%), lack of access to follow-up (44\%), inability to train the patient in the use of the kit (42\%), lack of knowledge surrounding the evidence for take-home naloxone (37\%), inadequate time in the clinical encounter (37\%), and lack of training in the prescription of naloxone (31\%).

Respondents' awareness of groups who may benefit from OEND programs is depicted in Figure 3. In addition to individuals at risk for overdose, $77 \%$ of respondents identified that friends and family members may also benefit from OEND programs. The groups that were identified as high-users of the ED, by respondents answering "always" or "frequently" to seeing them in their practice, were patients with known or suspected prescription opioid dependence or heroin use $(72 \%)$, patients using high doses of prescribed opioids (69\%), and patients with opioid use with known or suspected use of alcohol or benzodiazepines (68\%).

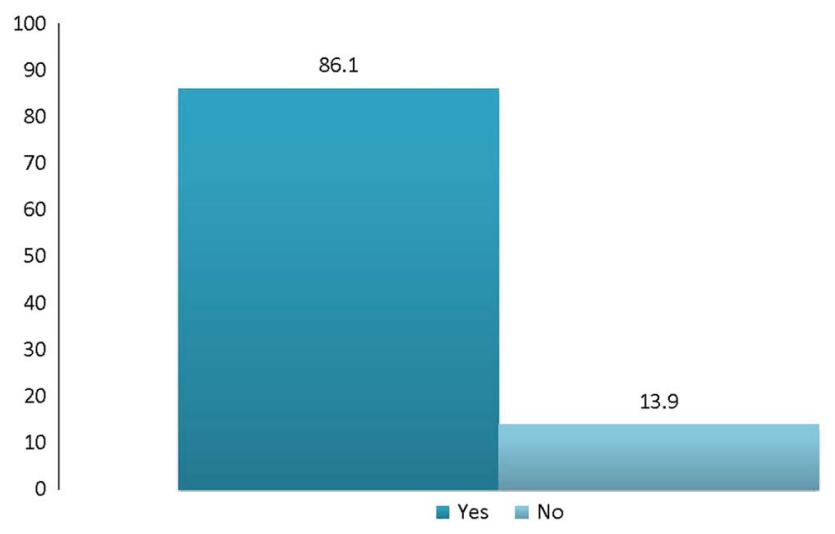

Figure 1. Survey Respondents' Willingness to Distribute Naloxone from the Emergency Department (\%). 


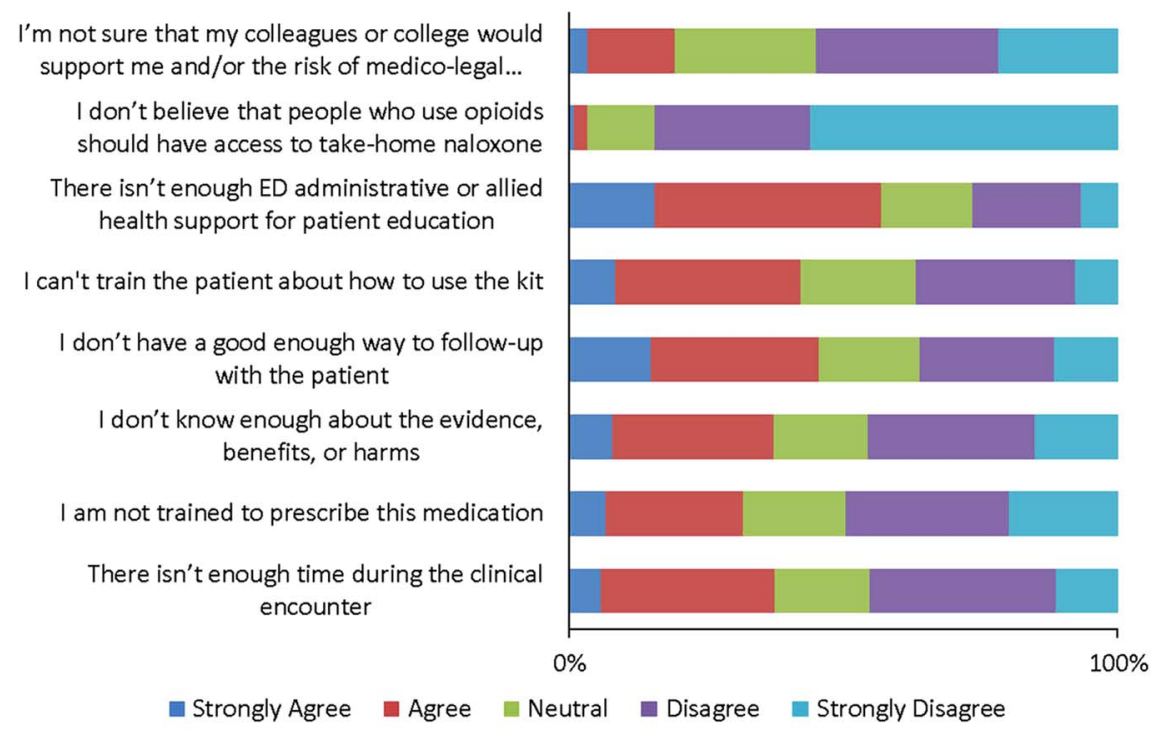

Figure 2. Survey Respondents' Identified Barriers to Distribution of Take-home Naloxone Kits from the Emergency Department.

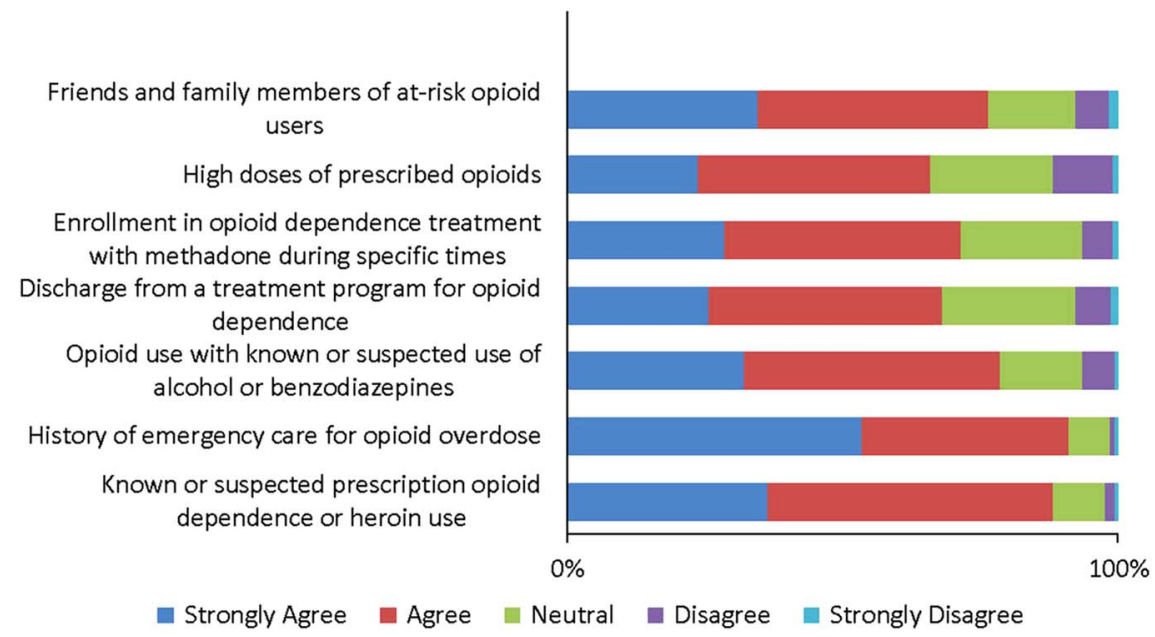

Figure 3. Survey Respondents' Awareness of Groups who may Benefit from Take-home Naloxone Programs.

When asked which member of the health care team was best suited to train recipients of OEND, emergency registered nurses and nurse practitioners were named most frequently (34\% and $27 \%$, respectively; Table 2$)$.

\section{DISCUSSION}

\section{Interpretation}

This study found that Canadian emergency physicians are generally aware of and willing to distribute naloxone from the ED. Our respondents were in agreement with pre-specified groups who would benefit from OEND programs $^{6,20}$ and identified lack of allied health support, time in the clinical encounter, access to follow-up, and lack of training as the most important barriers to implementation of these programs. Our findings that physicians with CCFP-EM designation were less likely to prescribe naloxone could be due to variations in the regional distribution of physicians, with more Fellow of the Royal College of Physicians of Canada (FRCPC) physicians working in larger cities where exposure to opioid overdose patients and ED-based OEND programs are more common. Provincial data are unfortunately lacking, which limits any conclusions about the willingness to distribute naloxone based on the scale of the opioid misuse problem in each Canadian province, a gap that has been recognized at a federal level and is currently being addressed by the Canadian Institute for Health Information. ${ }^{24}$ 


\begin{tabular}{l}
$\begin{array}{l}\text { Table 2. Member of the health care team identified as best } \\
\text { suited to train recipients of take-home naloxone kits }\end{array}$ \\
\hline Health care provider (\%)
\end{tabular}

\section{Previous reports}

The overwhelmingly positive attitude we found is different from what had been previously reported. ${ }^{25}$ This could be explained by increased exposure to OEND programs as opioid overdose deaths and drug-related ED visits continue to rise, in keeping with the majority of our survey respondents' reporting familiarity with these programs prior to this questionnaire. These programs have been widely adopted and sanctioned by respected institutions, especially in Canada with recent increased access to naloxone when it was removed from the Prescription Drug List and made available at no cost to people at risk for overdose. ${ }^{7}$ The minister of health has also recently signed an interim order authorizing the expedited availability of intranasal naloxone in Canada for easier delivery and decreased risk to the first-responder. ${ }^{26}$

Physicians recognize that people at risk for opioid overdose are frequently seen in the ED, and that this setting could be ideal for the implementation of OEND programs. The inclusion of opioid-associated resuscitative emergencies and OEND in the 2015 updated AHA guidelines for CPR and emergency cardiovascular care ${ }^{6}$ draws this intervention further into mainstream EM practice. A single-centre study of an OEND program in a Boston, Massachusetts ED found this setting to be feasible for education and naloxone distribution programs to a high-risk population in order to reduce opioid mortality. ${ }^{27}$ A recent study surveyed recipients of take-home naloxone from an ED in Vancouver, BC and reported that $68 \%$ of patients using opioids were willing to accept take-home naloxone, suggesting that the ED is an effective setting for this program. ${ }^{28}$ Further larger studies of ED-based programs are needed to evaluate implementation and cost-effectiveness. ${ }^{29}$

In our study, the willingness to distribute was not associated with practice setting or number of years in practice, making it unlikely that a generational difference could explain this change. This is comparable to a similar survey of American emergency physicians with regards to ED-based opioid harm reduction. ${ }^{21}$

\section{LIMITATIONS}

There are limitations to our study. Selection bias and non-response error are concerning, because respondents may have been more likely to have an interest or more positive sentiment toward the topic, and therefore may differ from non-respondents. This would increase our reported willingness to distribute naloxone. Our survey's low response rate may also limit external validity. This number is lower than previously reported physician response rates ${ }^{19}$ and may be explained by the design and length of the survey, a lack of engagement in the subject matter, or survey fatigue. We did receive responses from a large number of CAEP members (459) from all areas of the country, except Quebec. This brings forward the consideration of coverage error, given that the original language of distribution of the study by CAEP is English, despite the availability of French translation upon request. Emergency physicians who are not members of CAEP are also not represented in this population.

\section{IMPLICATIONS}

Our survey respondents identified time, institutional supports, knowledge, and training as barriers that should be addressed in the design of ED-based OEND programs to ensure success. Support from local and national leaders in EM, and education programs with focus on the evidence supporting naloxone distribution and recipient training may increase uptake of this intervention from the ED. Recent legislative changes in Canada empower any member of the patient's care team to participate in OEND programs, which should only increase their use. The results of this study could inform the development of a workshop at a national meeting with the goal of dissemination of evidence and training in harm-reduction strategies from the ED. Future research should focus on implementation studies of ED-based OEND programs to demonstrate meaningful impact and describe how our identified barriers were overcome, as well as education strategies to address knowledge deficits. 


\section{CONCLUSION}

Canadian emergency physicians are willing to distribute take-home naloxone to patients at risk for opioid overdose, but strategies that will facilitate opioid OEND implementation are necessary.

These data will inform the development of ED-based naloxone distribution programs, with emphasis on multidisciplinary training and education.

Acknowledgements: This study was supported by the University of Ottawa, Department of Emergency Medicine academic grant (2015-SP-10). AMO receives salary support from the Schwartz/Reisman Emergency Medicine Institute, the University of Toronto Department of Family and Community Medicine, and the Canadian Institutes of Health Research LL conceived the idea and secured research funding, collected data, and prepared the manuscript. LT, AMO, and IGS assisted with study design, supervised in the recruitment of participants and management of data, and revised the manuscript. All authors supervised in the conduct of the study and data collection, drafted the manuscript and/or contributed to its revision, and approved the final version. LL had full access to all of the data in the study and takes responsibility for the integrity of the data and the accuracy of the data analysis.

Competing interests: None declared.

\section{SUPPLEMENTARY MATERIAL}

To view supplementary material for this article, please visit https://doi.org/10.1017/cem.2017.390

\section{REFERENCES}

1. Centers for Disease Control and Prevention. About multiple causes of death, 1999-2014; 2015. Available at: http://wonder. cdc.gov/mcd-icd10.html.

2. CCENDU Bulletin. Deaths involving fentanyl in Canada (2009-2014); August 2015. Available at: http://www.ccsa.ca/ Resource\%20Library/CCSA-CCENDU-Fentanyl-DeathsCanada-Bulletin-2015-en.pdf (accessed 31 August 2016).

3. Madadi P, Hildebrandt D, Lauwers AE, et al. Characteristics of opioid-users whose death was related to opioidtoxicity: a population-based study in Ontario, Canada. PLoS One 2013;8:e60600.

4. Gomes T, Juurlink DN, Dhalla IA, et al. Trends in opioid use and dosing among socio-economically disadvantaged patients. Open Med 2011;5:13-22.

5. World Health Organization. Community management of opioid overdose. Geneva: WHO; 2014.

6. Lavonas EJ, Drennan IR, Gabrielli A, et al. Part 10: Special circumstances of resuscitation 2015 American Heart Association guidelines update for cardiopulmonary resuscitation and cmergency cardiovascular care. Circulation 2015;132: S501-18.

7. CCENDU Bulletin. The availability of take-home naloxone in Canada; March 2016. Available at: http://www.ccsa. ca/Resource\%20Library/CCSA-CCENDU-Take-HomeNaloxone-Canada-2016-en.pdf.

8. Clark AK, Wilder CM, Winstanley EL. A systematic review of community opioid overdose prevention and naloxone distribution programs. 7 Addict Med 2014;8:153-63.

9. Walley AY, Xuan Z, Hackman HH, et al. Opioid overdose rates and implementation of overdose education and nasal naloxone distribution in Massachusetts: interrupted time series analysis. $B M 7$ 2013;346:f174-f.

10. Oluwajenyo Banjo M, Tzemis D, Al-Qutub D, et al. A quantitative and qualitative evaluation of the British Columbia Take Home Naloxone program. CMA7 Open 2014;2:E153-61.

11. Dong KA, Taylor M, Wild CT, et al. Community-based naloxone: a Canadian pilot program. 7 Addict Med 2012;3: 4-9.

12. Leece PN, Hopkins S, Marshall C, et al. Development and implementation of an opioid overdose prevention and response program in Toronto, Ontario. Can 7 Public Health 2013;104:e200-4.

13. United Nations Office on Drugs and Crime/World Health Organization. Opioid overdose: preventing and reducing opioid overdose mortality. United Nations; 2013. Available at: https://www.unodc.org/docs/treatment/overdose.pdf (accessed 31 August 2016).

14. Doyon S, Aks SE, Schaeffer S. Expanding access to naloxone in the United States. 7 Med Toxicol 2014;10:431-4.

15. SAMHSA opioid overdose prevention toolkit. Rockville, MD: Substance Abuse and Mental Health Services Administration; 2016.

16. Canadian Institute for Health Information. Hospitalizations and emergency department visits due to opioid poisoning in Canada. Ottawa, ON: CIHI; 2016. Available at: https:// secure.cihi.ca/free_products/Opioid\%20Poisoning\%20Report \%20\%20EN.pdf.

17. Hasegawa K, Espinola JA, Brown DFM, et al. Trends in US emergency department visits for opioid overdose, 1993-2010. Pain Med 2014;15:1765-70.

18. Lacroix L, Stiell IG, Thurgur L, Orkin A. P071: Emergency department physician attitudes and perceived barriers to the implementation of take-home naloxone programs in Canadian emergency departments [abstract]. C7EM 2016;18(S1):S102.

19. Karen EA, Burns MM, Mark Duffett B, et al. A guide for the design and conduct of self-administered surveys of clinicians. CMA7 2008;179(3):245-52.

20. Orkin AM, Bingham $K$, Klaiman $M$, et al. An agenda for naloxone distribution research and practice: meeting report of the Surviving Opioid Overdose with Naloxone (SOON) International Working Group. 7 Addict Res Ther 2015;6:212.

21. Samuels EA, Dwyer K, Mello MJ, et al. Emergency department-based opioid harm reduction: moving physicians from willing to doing. Acad Emerg Med 2016;23:455-65.

22. Carter CI, Graham B. Opioid overdose prevention and response in Canada. Vancouver: Canadian Drug Policy Coalition; 2013. Available at: https://drugpolicy.ca/wp-content/uploads/2013/ 01/CDPC_OverdosePreventionPolicy_Final_July2014.pdf. 
23. Dillman DA. Mail and web-based survey: the tailored design method. New York: John Wiley \& Sons; 2000.

24. Government of Canada. Joint Statement of Action to Address the Opioid Crisis; 2016. Available at: https://www. canada.ca/en/health-canada/services/substance-abuse/opioidconference/joint-statement-action-address-opioid-crisis.html (accessed 9 February 2016).

25. Beletsky L, Ruthazer R, Macalino GE, et al. Physicians' knowledge of and willingness to prescribe naloxone to reverse accidental opiate overdose: Challenges and opportunities. 7 Urban Health 2007;84(1):126-36.

26. Government of Canada. Interim order respecting naloxone hydrochloride nasal spray; 2016. Available at: https://www. canada.ca/en/health-canada/services/drugs-health-products/ drug-products/announcements/interim-order-respectingnaloxone-hydrochloride-nasal-spray.html.

27. Dwyer K, Walley A, Langlois B, et al. Opioid education and nasal naloxone rescue kits in the emergency department. West 7 Emerg Med 2015;16:381-4.

28. Kestler A, Buxton J, Meckling G, et al. Factors associated with participation in an emergency department-based takehome naloxone program for at-risk opioid users. Ann Emerg Med 2017;69(3):340-6.

29. Coffin PO, Sullivan SD. Cost-effectiveness of distributing naloxone to heroin users for lay overdose reversal. Ann Intern Med 2013;158:1-9. 